\title{
Role of microperimetry in evaluating disease progression in age-related macular degeneration: a scoping review
}

\author{
Gopinath Madheswaran (1) Pinaz Nasim (1) Shonraj Ballae Ganeshrao (1) • \\ Rajiv Raman (D) Ramesh S. Ve(i)
}

Received: 27 June 2021 / Accepted: 18 December 2021 / Published online: 7 January 2022

(C) The Author(s) 2022

\begin{abstract}
Purpose Recent research has found variable evidence on the role of mesopic and dark-adapted scotopic microperimetry assessment in age-related macular degeneration. This scoping review summarises how mesopic and scotopic microperimetry can be used to assess disease progression in agerelated macular degeneration and identifies gaps in the literature.

Methods A population, concept, and context approach was used to develop the search strategy. Ovid MEDLINE, EMBASE, Cochrane Library, PubMed, CINAHL Plus, Web of Science, and SCOPUS databases were used to conduct the literature search. The key search terms used in the databases were age-related macular degeneration and microperimetry.
\end{abstract}

Supplementary Information The online version contains supplementary material available at https://doi.org/10.1007/ s10792-021-02170-9.

G. Madheswaran - P. Nasim - S. Ballae Ganeshrao • R. S. Ve $(\square)$

Department of Optometry, Manipal College of Health Professions, Manipal Academy of Higher Education,

Manipal, Karnataka, India

e-mail: ramesh.sve@manipal.edu

R. Raman

Shri Bhagwan Mahavir Vitreoretinal Services, Sankara

Nethralaya, Chennai, Tamilnadu, India
Results Twelve studies were eligible and included in the review. All the studies $(n=12)$ were conducted in European countries [Germany (9), Italy (2), and the United Kingdom (1)]. The mesopic and scotopic sensitivities were measured using the Nidek scotopic microperimeter (MP1-S) $(n=6)$, scotopic Macular Integrity Assessment device (S-MAIA) $(n=5)$, and both MP1-s and S MAIA $(n=1) .83 .3 \%(n=10)$ studied (cross-sectional design) on mesopic, scotopic microperimetry and found reduced rod (scotopic) photoreceptors sensitivities compared to cone (mesopic) photoreceptors sensitivities in patients with small and reticular pseudodrusen despite having good visual acuity. Only $16.7 \%(n=2)$ of studies followed participants with reticular drusen/large drusen for three years (longitudinal design) and found reduced scotopic over mesopic sensitivity at baseline and localized mesopic with profound scotopic sensitivity loss during follow-ups.

Conclusion Scotopic sensitivity is a better functional indicator than mesopic sensitivity to understand early and intermediate age-related macular degeneration progression. The evidence from longitudinal studies is debatable due to the limited stimuli range of existing microperimeters, smaller sample size, and lost followups.

Keywords Age-related macular degeneration . Mesopic microperimetry $\cdot$ Microperimeter $\cdot$ Fundus 
controlled perimetry $\cdot$ Scotopic microperimetry ·

Scoping review

\section{Introduction}

Age-related macular degeneration (AMD) is the third most leading cause of irreversible blindness in the elderly population [1]. The global prevalence of AMD is expected to increase to 10 million by 2040 , from 1.8 million in 2020 [2, 3]. AMD is classified based on clinical and imaging findings [4, 5]. Early and intermediate AMD are characterized by the presence of drusen of different sizes and quantities, as well as pigmentary abnormalities [5]. The signs of advanced AMD include choroidal neovascularisation and or geographic atrophy (GA). Depending on the presence or absence of neovascularization, AMD may also be divided into two groups: dry or non-neovascular AMD (or GA) and wet or neovascular AMD (nAMD). Visual impairment in early and intermediate AMD is less severe than in advanced AMD [5, 6]. Wet AMD (nAMD) causes a sudden loss of vision, whereas dry AMD (GA) leads to a gradual, progressive loss of vision [7]. The progression from early or intermediate to advanced AMD is evaluated by comparing structural damage of the retina and functional change in vision [8]. The gold-standard treatment for nAMD is the anti-vascular endothelial growth factor, which has improved prognosis. However, no specific treatment is available for dry AMD [6, 9]. Management of early and intermediate AMD involves closer follow-up examinations of both structural and functional changes.

Microperimetry or fundus-oriented perimetry plays a vital role in testing the foveal sensitivity in AMD $[10,11]$. Recent advances in microperimeter include mesopic, scotopic sensitivity tests that provide better diagnostic and prognostic information for AMD [12]. Mesopic and scotopic sensitivity, which measures the cone and rod functions, are estimated by modifying the background illumination of the microperimeter $[13,14]$.

Commercially available microperimeters such as the Nidek microperimeter (MP1) (NIDEK Technologies, Padova, Italy) was modified by adding the neutral density (ND) filter (MP1-S) [15] to extend the range of stimulus intensity $[13,16]$. MP1-S was limited due to its ceiling effects, filter selection based on AMD severity, longer test duration, and poor fixation [16-18]. The latest Nidek MP version 3, which includes scotopic testing [19], claims to have overcome the MP1-S's limitations. However, no studies have evaluated AMD patients' mesopic and scotopic sensitivities using the latest Nidek MP Version 3. Macular Integrity Assessment (MAIA) microperimeter (CenterVue, Padova, Italy), with scotopic testing (S-MAIA) device, was designed to perform the mesopic and dark-adapted scotopic tests using two colored (cyan and red) light-emitting diodes [20]. The use of two-colored stimuli helps determine distinct sensitivity loss of cone and rod photoreceptor's cells [14, 21-23]. The latest version of S-MAIA features a rapid test protocol and an increased range of stimuli intensity (0-36 decibel), reducing ceiling effects [24].

Recent evidence suggests that scotopic sensitivity is a good functional indicator to assess progression in AMD [13, 23]. The rod photoreceptors (scotopic sensitivity) functions are significantly affected in early and intermediate AMD without affecting the bestcorrected visual acuity (BCVA) [8]. Studies reported compared to normal, mesopic and scotopic sensitivity reduction was observed in AMD [14, 16, 21, 23, 25]. A study by Montesano et al. [25] reported that mesopic sensitivity was well correlated with morphological changes than scotopic sensitivity. However, other studies have suggested scotopic sensitivity as a better functional indicator [13, 16, 23, 26, 27] for detecting AMD progression, associated with an increased risk of blindness.

Scoping reviews offer an effective approach for identifying and mapping the available evidence, providing critical concepts and key features in a specific study area [28]. The key objectives of this scoping review are: (a) To understand the role of mesopic and scotopic microperimetry sensitivities in AMD, (b) To understand if mesopic and scotopic sensitivities help identify patients progressing from early or intermediate AMD, (c) To map the research carried out in this field systematically, and (d) To find gaps in the existing literature. 


\section{Methodology}

The scoping review protocol was registered (OSF registries) [29] and followed the elaborated methodological framework for scoping reviews by Levac et al. [30, 31]. The steps followed were: (1) identification of the research objectives; (2) identification of relevant studies; (3) screening and selection of studies; (4) charting the data; and (5) collating, summarizing, and reporting the results.

Identification of the research objective

The research objectives discussed in the introduction were formulated. A search strategy was developed using the population, concept, and context (PCC) approach [32].

- Population People with age-related macular degeneration,

- Concept Mesopic and scotopic microperimetry to evaluate disease progression,

- Context No limit to gender, race, and geographic location.

Identification of relevant studies

Electronic records were searched using Ovid MEDLINE, EMBASE, Cochrane Library, PubMed, CINAHLPlus, Web of Science, and SCOPUS on 10th February 2021. Search terms used in the database were "age-related macular degeneration", "scotopic microperimetry", "mesopic microperimetry", "fundus controlled perimetry", and the related terms that are used provided in online resource 1 . In addition, other sources such as theses, dissertations, and grey literature were searched. There were no gender or race restrictions.

Screening and selection of studies

Titles and abstracts of the identified articles were screened based on the following inclusion and exclusion criteria. This review included subjects with defined stages of age-related macular degeneration by Ferris et al. [5] or Age-Related Eye Disease Study [4]; use of microperimetry or mesopic and scotopic microperimetry, or dark-adapted perimetry. The review excluded study subjects with any other retinal pathologies; studies that do not define AMDs category; studies that do not use mesopic and scotopic microperimetry; studies that do not provide a clear concept and methodology; studies not published full text in scientific journals, English language; conference abstracts.

Studies were imported into Mendeley Desktop [33] to remove the duplicates. The studies were exported to Microsoft Excel 2013 for management and selection based on titles and abstracts by two authors. Studies were selected independently and blind to the decision of the other authors. Studies that failed to meet the criteria were removed. These process differences were resolved by a third reviewer, leading to an agreement. Later, the full text of eligible studies was acquired and read. The details for the exclusion were noted. Also, cited references were searched from the extracted articles with the inclusion and exclusion criteria. The study selection process was documented in a flow chart, according to the Preferred Items guidelines for Systematic Review and Meta-Analysis Reports (PRISMA-ScR) for scoping reviews [34].

Charting the data

A predetermined form was used to chart the data from the selected studies using Microsoft Excel. Data extracted from the selected studies included study demographics (author, year of publication), methodology (purpose, sample size, and population), results, and key findings. The data extraction, charting were performed independently by two authors and reviewed by a third author.

Collating, summarizing, and reporting the results

The important information was categorized and tabulated from the included studies by two authors, verified, and approved by a third author. Finally, the current gaps in research on mesopic and scotopic microperimetry in age-related macular degeneration were listed.

\section{Results}

The database search identified a total of 2031 articles and two dissertations. (Fig. 1). The remaining records after duplicates removal were 605 . Those articles were 
Fig. 1 Flow chart on literature search and study selection

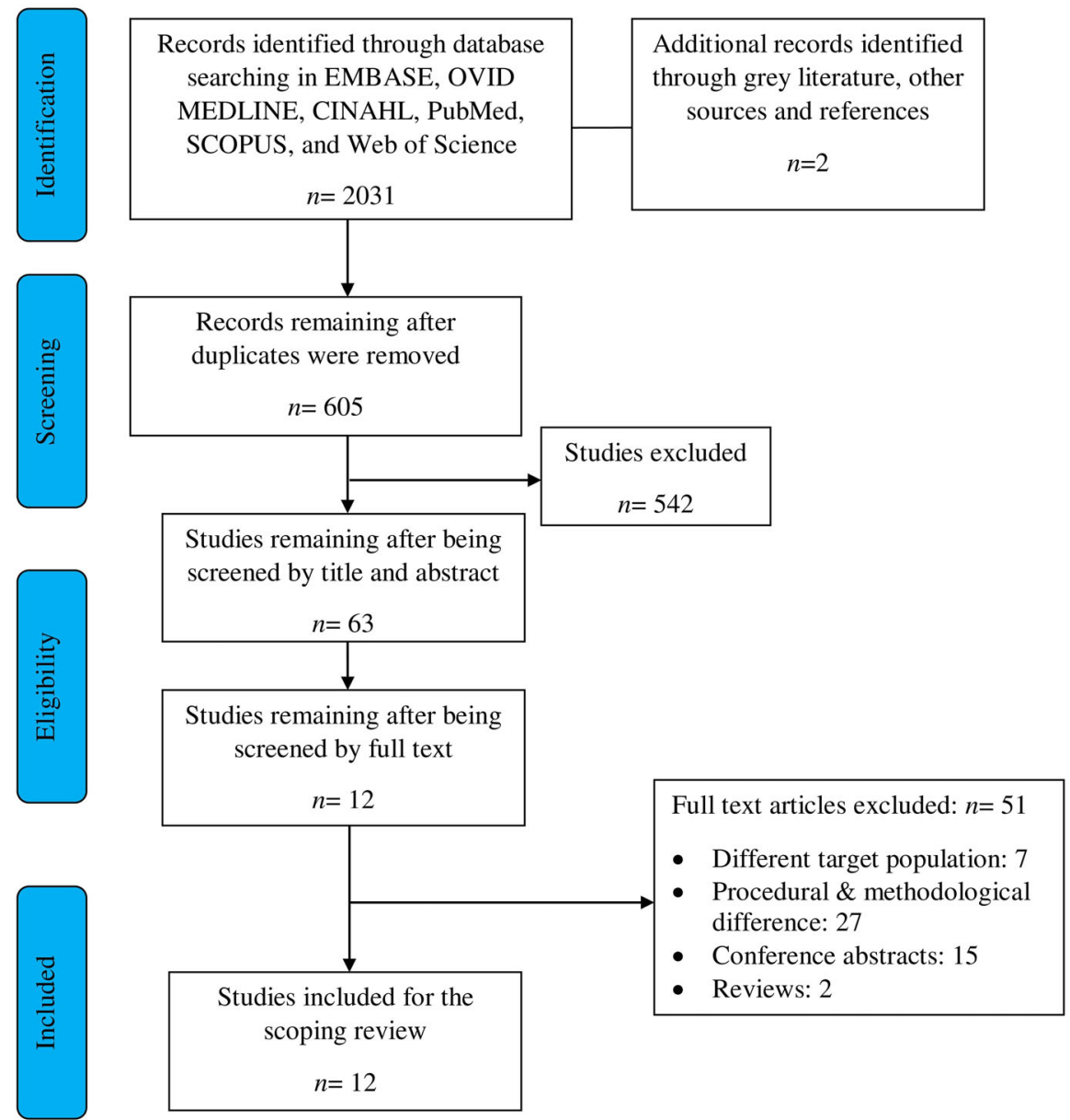

subjected to titles and abstract screening, and 542 were excluded. The remaining 63 articles were obtained as full text and read, of which 51 articles were excluded. The major reasons for exclusion were the procedural and methodological differences (27), conference abstracts (15), diverse target population (Stargardt's disease, mixed retinal diseases, and healthy normal) (7), and reviews (2). Two dissertations [35, 36] were obtained as grey literature in a web search; however, they did not meet our criteria and were excluded. Of the 51 articles excluded, 19 articles used microperimetry as a tool for assessing AMD. However, these studies did not measure scotopic or mesopic sensitivities and were excluded. The detailed list for exclusion is provided in online resource 2. A total of twelve articles were included in the final review.

Most of the included studies were done in Germany $n=9(75 \%)$, followed by Italy $n=2(16.7 \%)$ and United Kingdom $n=1(8.3 \%)$. Of the included studies, $n=10(83.3 \%)$ followed cross-sectional study design [13, 14, 16, 21-23, 25-27, 37], and $n=2(16.7 \%)$ followed longitudinal analysis [38, 39]. Six studies [13, 16, 26, 37-39] included a modified version of microperimeter (MP1-S) [15], five studies used scotopic MAIA (S-MAIA) microperimeter [21-23, 25, 27] and, one study [14] used both MP1$\mathrm{S}$ and S MAIA microperimeters to measure scotopic, mesopic sensitivities. Table 1 summarizes the findings of cross-sectional studies, including the number of participants, mean age, BCVA, mesopic, scotopic sensitivities, and differences in sensitivities between cases (AMD) controls. Mesopic sensitivity is not different between early AMDs [(small drusen and reticular pseudodrusen (RPD)] and healthy controls $(p>0.05)$, as shown in Table 1 . However, there is a statistically significant difference in both mesopic and scotopic sensitivities between intermediate AMD (large drusen) and healthy controls $(p<0.05)$. 
Table 1 Study details, no of participants, mean age, BCVA, mesopic, scotopic sensitivities, and differences in sensitivities among cases and controls from cross-sectional studies

\begin{tabular}{|c|c|c|c|c|c|c|c|}
\hline Study & $\begin{array}{l}\text { Participants } \\
\text { (no of eyes) }\end{array}$ & $\begin{array}{l}\text { Age } \\
\text { (years) }\end{array}$ & $\begin{array}{l}\text { Mean } \\
\text { BCVA } \\
(\log \\
\text { MAR) }\end{array}$ & $\begin{array}{l}\text { Mesopic } \\
\text { sensitivity } \\
\text { mean (SD) } \\
(\mathrm{dB})\end{array}$ & $\begin{array}{l}\text { Scotopic } \\
\text { sensitivity } \\
\text { mean (SD) } \\
(\mathrm{dB})\end{array}$ & $\begin{array}{l}\text { Difference in } \\
\text { mesopic sensitivity } \\
\text { (cases-controls) ( } p \text { - } \\
\text { value) }\end{array}$ & $\begin{array}{l}\text { Difference in } \\
\text { scotopic sensitivity } \\
\text { (cases-controls) ( } p \text { - } \\
\text { value) }\end{array}$ \\
\hline \multirow{2}{*}{$\begin{array}{l}\text { Nebbioso et al. } \\
\text { [13], Italy (MP- } \\
\text { 1S) }\end{array}$} & $\begin{array}{l}\text { Hard drusen } \\
\quad(n=12)\end{array}$ & $\begin{array}{l}66.3 \\
(3.4)\end{array}$ & 0.0 & $19.07(0.21)$ & $5.20(1.2)$ & \multirow[t]{2}{*}{$1.9 \mathrm{~dB}(p>0.05)$} & \multirow[t]{2}{*}{$2.5 \mathrm{~dB}(p<0.003)^{*}$} \\
\hline & $\begin{array}{l}\text { Healthy } \\
\text { controls } \\
(n=12)\end{array}$ & $\begin{array}{l}67.1 \\
(7.5)\end{array}$ & 0.0 & $19.17(0.99)$ & $7.70(0.2)$ & & \\
\hline \multirow{2}{*}{$\begin{array}{l}\text { Steinberg et al. } \\
2015 \text { [16], } \\
\text { Germany (MP- } \\
\text { 1S) }\end{array}$} & $\begin{array}{l}\text { Early/iAMD } \\
\quad(n=18)\end{array}$ & $\begin{array}{l}74.7 \\
(7.1)\end{array}$ & 0.0 & $17.2(3.61)$ & $13.5(2.9)$ & \multirow[t]{2}{*}{$0.9 \mathrm{~dB}(p=0.03)$} & \multirow[t]{2}{*}{$4.8 \mathrm{~dB}(p \leq 0.001)^{*}$} \\
\hline & $\begin{array}{l}\text { Late AMD } \\
\quad(n=4)\end{array}$ & $\begin{array}{l}74.7 \\
(7.1)\end{array}$ & 0.2 & $18.1(2.40)$ & $18.3(3.1)$ & & \\
\hline \multirow{2}{*}{$\begin{array}{l}\text { Steinberg et al. } \\
\text { [34], Germany } \\
\text { (MP-1S) }\end{array}$} & $\begin{array}{l}\text { RPD } \\
\quad(n=20)\end{array}$ & $\begin{array}{l}75.8 \\
(8.5)\end{array}$ & 0.1 & $17.2(2.50)$ & $12.8(3.3)$ & \multirow[t]{2}{*}{$1.2 \mathrm{~dB}(p=0.01)$} & \multirow[t]{2}{*}{$5.4 \mathrm{~dB}(p<0.001)^{*}$} \\
\hline & $\begin{array}{l}\text { Healthy } \\
\text { controls } \\
(n=20)\end{array}$ & $\begin{array}{l}75.5 \\
\quad(10.1)\end{array}$ & 0.0 & $18.4(2.50)$ & $18.2(2.2)$ & & \\
\hline \multirow{2}{*}{$\begin{array}{l}\text { Sassmannshausen } \\
\text { et al. [25], } \\
\text { Germany (MP- } \\
\text { 1S) }\end{array}$} & $\begin{array}{l}\text { Intermediate } \\
\text { AMD } \\
(n=35)\end{array}$ & $\begin{array}{l}70.9 \\
(8.2)\end{array}$ & 0.1 & $16.9(3.00)$ & $14.0(3.7)$ & \multirow[t]{2}{*}{-} & \multirow[t]{2}{*}{-} \\
\hline & $\begin{array}{l}\text { Healthy } \\
\text { controls } \\
(n=29)\end{array}$ & $\begin{array}{l}75.3 \\
(5.2)\end{array}$ & 0.0 & NR & NR & & \\
\hline \multirow[t]{2}{*}{$\begin{array}{l}\text { Pfau et al. [22], } \\
\text { Germany (S- } \\
\text { MAIA) }\end{array}$} & $\begin{array}{l}\text { Drusen } \\
\quad(n=24)\end{array}$ & $\begin{array}{l}69.4 \\
\quad(12.6)\end{array}$ & 0.07 & $24.9(2.40)$ & $\begin{array}{l}10.1(3.0) \\
\text { cyan } 12.2 \\
(2.4) \mathrm{red}\end{array}$ & \multirow[t]{2}{*}{-} & \multirow[t]{2}{*}{-} \\
\hline & $\begin{array}{l}\text { Healthy } \\
\text { controls } \\
(n=20)\end{array}$ & $\begin{array}{l}61.7 \\
\quad(12.4)\end{array}$ & 0.0 & NR & NR & & \\
\hline \multirow[t]{2}{*}{$\begin{array}{l}\text { Welker et al. [21], } \\
\text { Germany (S- } \\
\text { MAIA) }\end{array}$} & $\begin{array}{l}\text { Intermediate } \\
\text { AMD } \\
(n=23)\end{array}$ & $\begin{array}{l}67.3 \\
(8.2)\end{array}$ & 0.4 & $23.01(3.30)$ & $19.92(4.06)$ & \multirow[t]{2}{*}{$2.62 \mathrm{~dB}(p<0.01)^{*}$} & \multirow[t]{2}{*}{$2.49 \mathrm{~dB}(p<0.01)^{*}$} \\
\hline & $\begin{array}{l}\text { Healthy } \\
\text { controls } \\
(n=29)\end{array}$ & $\begin{array}{l}61.3 \\
(5.2)\end{array}$ & 0.0 & $25.63(2.29)$ & $22.41(2.54)$ & & \\
\hline \multirow{2}{*}{$\begin{array}{l}\text { Corvi et al. [14], } \\
\text { Italy (MP1-S, S } \\
\text { MAIA) }\end{array}$} & $\begin{array}{l}\text { Drusen } \\
\quad(n=15)\end{array}$ & $\begin{array}{l}72.8 \\
(7.1)\end{array}$ & 0.0 & $25.44(4.3)$ & $13.25(5.5)$ & \multirow[t]{2}{*}{$\begin{array}{l}2.07 \mathrm{~dB} \\
\quad(p<0.001)^{*}\end{array}$} & \multirow[t]{2}{*}{$\begin{array}{l}4.99 \mathrm{~dB} \\
\quad(p<0.001)^{*}\end{array}$} \\
\hline & $\begin{array}{l}\text { RPD } \\
\quad(n=14)\end{array}$ & $\begin{array}{l}78.2 \\
(7.2)\end{array}$ & 0.0 & $23.37(4.2)$ & $8.26(5.4)$ & & \\
\hline \multirow{2}{*}{$\begin{array}{l}\text { von der Emde } \\
\text { et al. [27], } \\
\text { Germany (S- } \\
\text { MAIA) }\end{array}$} & $\begin{array}{l}\text { Neovascular } \\
\text { AMD } \\
(n=50)\end{array}$ & $\begin{array}{l}76.1 \\
(7.6)\end{array}$ & 0.38 & NR & $\begin{array}{l}\text { NR (cyan) } \\
\text { NR (red) }\end{array}$ & \multirow[t]{2}{*}{-} & \multirow[t]{2}{*}{$\begin{array}{l}2.63 \mathrm{~dB} \\
\quad(p<0.001)^{*}\end{array}$} \\
\hline & $\begin{array}{l}\text { Healthy } \\
\text { controls } \\
(n=29)\end{array}$ & $\begin{array}{l}55.9 \\
\quad(16.9)\end{array}$ & 0.03 & NR & NR & & \\
\hline \multirow[t]{2}{*}{$\begin{array}{l}\text { Pondorfer et al. } \\
\text { [23], Germany } \\
\text { (S- MAIA) }\end{array}$} & $\begin{array}{l}\text { Intermediate } \\
\text { AMD } \\
(\mathrm{n}=38)\end{array}$ & $\begin{array}{l}69.1 \\
(7.5)\end{array}$ & 0.2 & $23.1(1.80)$ & $20.0(2.7)$ & \multirow[t]{2}{*}{$2.8 \mathrm{~dB}(p<0.01)^{*}$} & \multirow[t]{2}{*}{$2.5 \mathrm{~dB}(p<0.01)^{*}$} \\
\hline & $\begin{array}{l}\text { Healthy } \\
\text { controls } \\
(n=24)\end{array}$ & $\begin{array}{l}61.7 \\
(6.1)\end{array}$ & 0.0 & $25.9(1.60)$ & $22.5(1.5)$ & & \\
\hline
\end{tabular}


Table 1 continued

\begin{tabular}{|c|c|c|c|c|c|c|c|}
\hline Study & $\begin{array}{l}\text { Participants } \\
\text { (no of eyes) }\end{array}$ & $\begin{array}{l}\text { Age } \\
\text { (years) }\end{array}$ & $\begin{array}{l}\text { Mean } \\
\text { BCVA } \\
(\log \\
\text { MAR) }\end{array}$ & $\begin{array}{l}\text { Mesopic } \\
\text { sensitivity } \\
\text { mean (SD) } \\
(\mathrm{dB})\end{array}$ & $\begin{array}{l}\text { Scotopic } \\
\text { sensitivity } \\
\text { mean (SD) } \\
(\mathrm{dB})\end{array}$ & $\begin{array}{l}\text { Difference in } \\
\text { mesopic sensitivity } \\
\text { (cases-controls) ( } p \text { - } \\
\text { value) }\end{array}$ & $\begin{array}{l}\text { Difference in } \\
\text { scotopic sensitivity } \\
\text { (cases-controls) ( } p \text { - } \\
\text { value) }\end{array}$ \\
\hline \multirow[t]{2}{*}{$\begin{array}{l}\text { Montesano et al. } \\
\text { [25], United } \\
\text { Kingdom (S- } \\
\text { MAIA) }\end{array}$} & $\begin{array}{l}\text { Drusen } \\
\qquad(n=43)\end{array}$ & $72(12)$ & 0.1 & $24.32(2.48)$ & $\begin{array}{l}10.43(2.9) \\
\text { cyan } \\
12.53 \\
\text { (3.6) red }\end{array}$ & $1.16 \mathrm{~dB}(p>0.05)$ & NR \\
\hline & $\begin{array}{l}\text { Healthy } \\
\text { controls } \\
(n=56)\end{array}$ & $62(5)$ & 0.0 & $25.48(1.62)$ & $\begin{array}{l}11.74(2.0) \\
\text { cyan } \\
13.23 \\
(1.7) \text { red }\end{array}$ & & \\
\hline
\end{tabular}

*Indicate statistically significant

$S D$ standard deviation, $B C V A$ best-corrected visual acuity, $d B$ decibels, $R P D$ reticular pseudo drusen

Only two studies [38, 39] longitudinally followed up patients with RPD and large drusen over three years. At baseline, there was a significant difference in mesopic to scotopic sensitivity between healthy controls and RPD cases [38] $(p<0.001)$. In addition, eyes with large drusen had lower mesopic and scotopic sensitivity at baseline than control participants [39] $(p<0.001)$. Table 2 shows study details, number of participants, mean age, BCVA, mesopic, scotopic sensitivities, retinal thickness, and differences in AMD cohorts at 12, 24, and 36 months from longitudinal studies. From Table 2, it is evident that in both cases of RPD and large drusen, loss of mesopic and scotopic sensitivities are significantly higher during follow-up visits $(p<0.001)$. In addition, in the second and third follow-ups, there was a significant decrease in total retinal thickness at the level of drusen $(p<0.001)$.

Table 3 compares the mesopic and scotopic sensitivity testing protocols between MP1-S and S-MAIA.

\section{Discussion}

This scoping review summarises the important studies on scotopic and mesopic microperimetry in the results section. The discussion has been categorized as follows: (1) Role of mesopic and scotopic microperimetry in AMD, and (2) Mesopic and scotopic microperimetry in detecting the progression of AMD.
Role of mesopic and scotopic microperimetry in AMD

Central visual acuity is preserved in the early stages of AMD [40]. Despite having good visual acuity ( $\geq 6 / 9)$ in most participants, studies by Nebbioso et al. [13] and Steinberg et al. [16] found a significant reduction in scotopic sensitivity at the drusen and RPD locations. These findings correlate well with patient-reported symptoms of difficulties in dark-adapted environments. In addition, participants with RPD showed a localized decrease in scotopic sensitivity over mesopic compared to those with drusen [16, 17]. Steinberg et al. [16, 37] and Sabmannshausen et al. [26] also showed a difference in retinal thickness between RPD and drusen. These findings are in line with previous studies [41, 42].

In dark-adapted two-colour microperimetry, reduced scotopic cyan sensitivity was observed, suggesting that rod photoreceptor cells are more impaired than cones in early AMD [22]. Welker et al. [21] reported reduced mesopic and scotopic (cyan, red) sensitivities in intermediate AMD due to moderate visual impairment $[43](\leq 6 / 18)$. von der Emde et al. [27] observed a similar sensitivity reduction in neovascular AMD. In contrast with the previous study methods [13, 16, 21, 26, 27, 37], Corvi et al. [14] used two instruments to obtain mesopic (S MAIA) and scotopic (MP1-S) sensitivities. Corvi et al. [14] found that RPD had reduced scotopic and mesopic functions and better performance in mesopic 


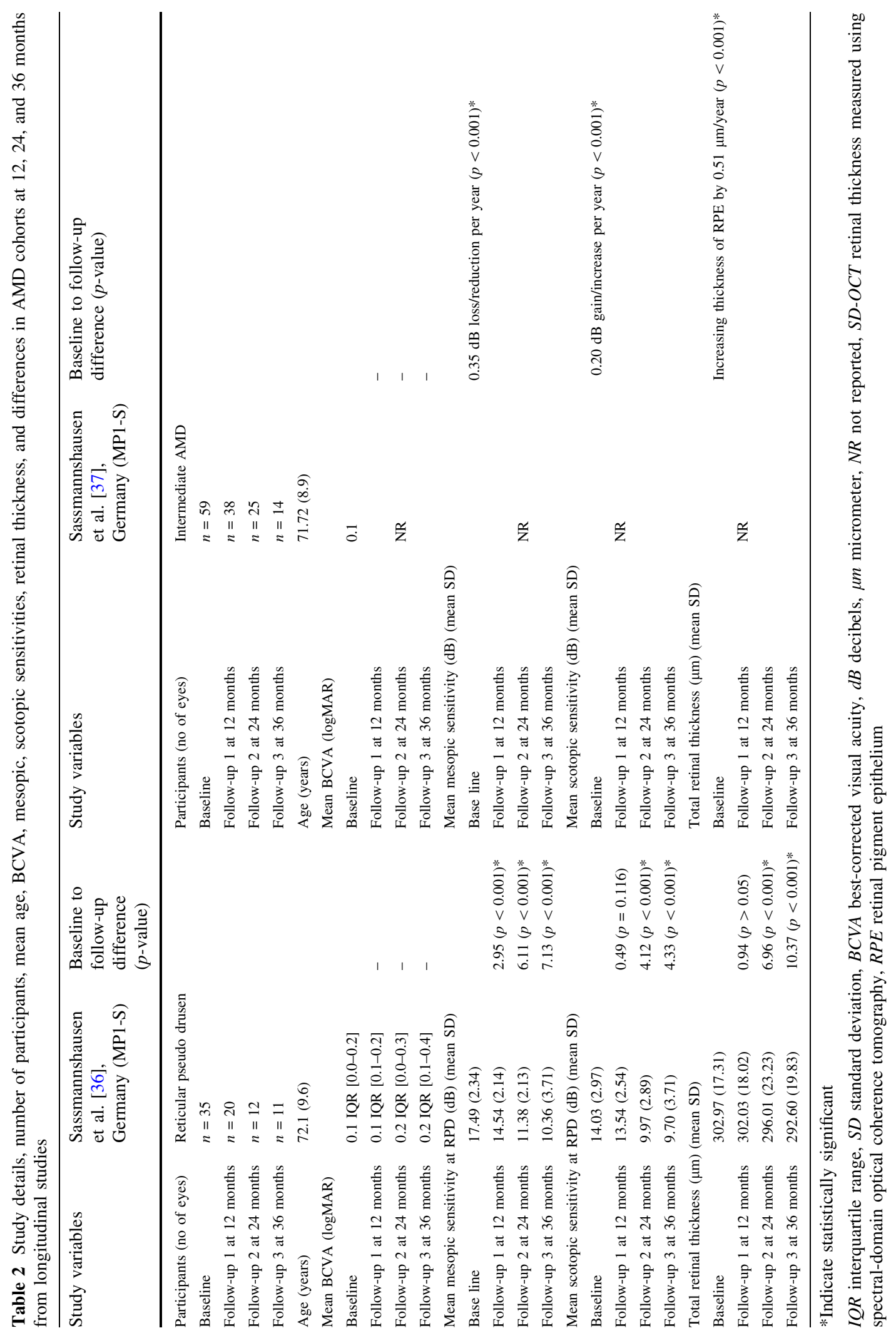




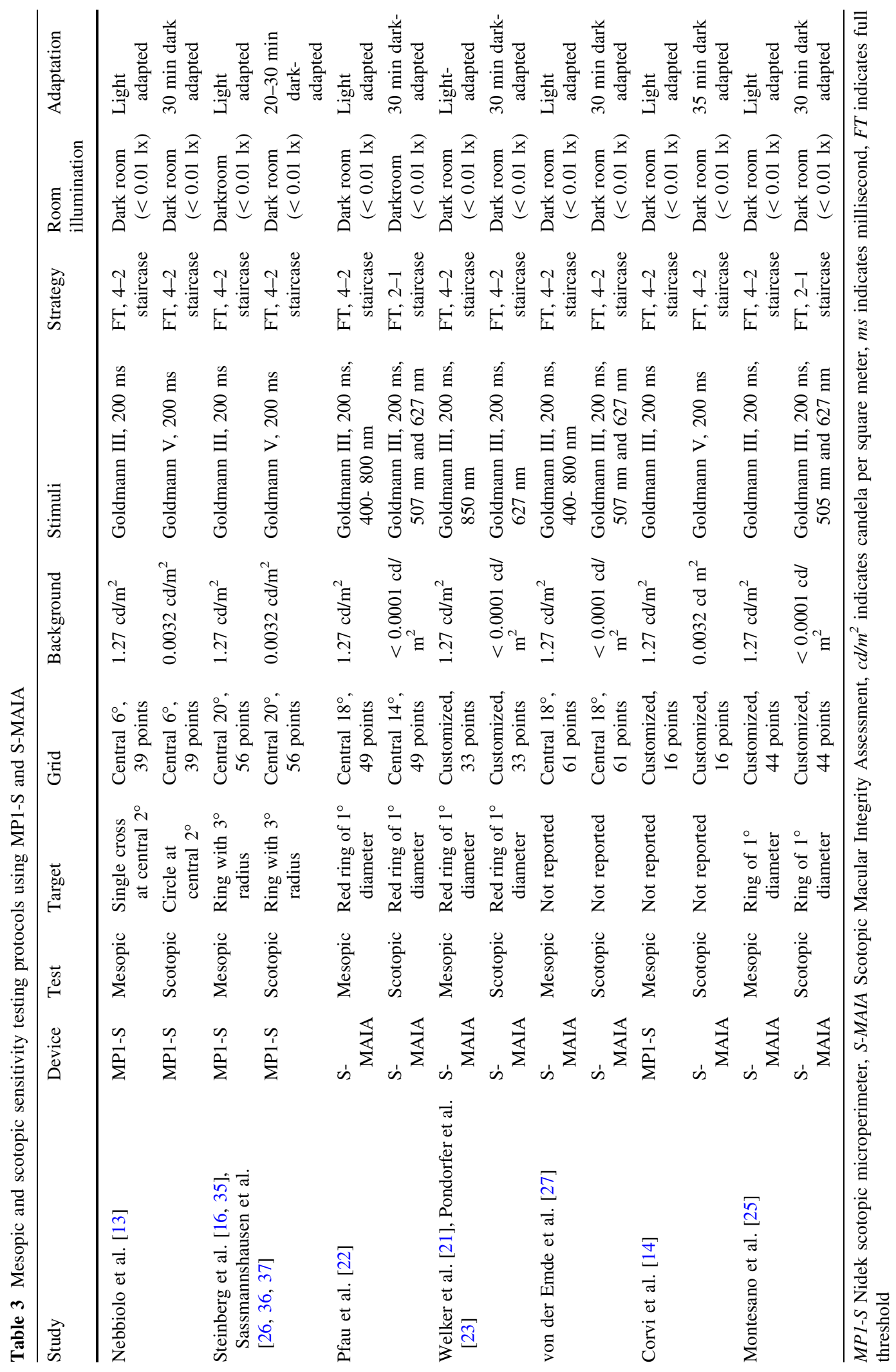


tests with fewer test points and shorter test duration when using S-MAIA.

Pondorfer et al. [23] also reported reduced mesopic, dark-adapted sensitivities in intermediate AMD. They suggested that mesopic function served better than scotopic functions and concluded that it might overperform mesopic for clinical studies [23]. In comparison with Pfau et al. [22], the notable differences were the increased stimuli intensity, reduced ceiling effect, and participants included with intermediate AMD [23]. Montesano et al. [25] observed mesopic and dark-adapted scotopic (cyan and red) reduction in AMD. Furthermore, mesopic microperimetry outperformed scotopic microperimetry in terms of predicting progression through morphological changes [25].

Mesopic and scotopic microperimetry in detecting the progression of AMD

Longitudinal studies suggest that comparing the structural and functional changes is a key to progression analysis in AMD [44, 45]. Sassmannshausen et al. [38] observed that participants with RPD had reduced scotopic sensitivity over mesopic at baseline than controls, as well as an equal loss of mesopic and scotopic sensitivity over time (3 years) in RPD. A significant change in the drusen size was the primary reason for reduced mesopic and scotopic sensitivities. Sassmannshausen et al. [39] reported localized mesopic and profound scotopic sensitivity loss in patients with intermediate AMD compared to baseline. There was a significant loss of mesopic sensitivity in follow-ups, but an increase in scotopic sensitivity was observed in patients with large drusen. However, both studies were limited, with a loss in the follow-up of small samples.

In the seven of twelve articles included, only one eye of the patient was examined and included for analysis. However, five articles [16, 26, 37-39] had included both eyes and did not perform between eyes statistical correction to include both eyes. There is a significant between-eye correlation for dry AMD, and statistical correction must be used if both eyes are included in the analysis [46].

\section{Strengths and limitations}

Scoping review methodology allowed for the collection of diverse literature with a comprehensive search using seven databases. However, the review also had several limitations. First, the subjective nature of the article selection due to the scoping review methodology to collect all evidence that might contribute to the study aim. Second, only studies that used commercially available microperimeters were considered; studies that used modified versions or were still in the development stage were not included. Finally, abstracts from conferences were excluded; however, many abstracts were later published in full text. Despite these limitations, this scoping review followed the rigor methodology advocated by Arksey and O’Malley [30], Levac et al. [31], and detailed reporting guidelines and their extensions by Tricco et al. [34].

\section{Recommendations}

Key findings

Mesopic microperimetry takes less time and is easy to perform, though it does not measure the photoreceptors in the retina compared to scotopic microperimetry. Scotopic microperimetry is more sensitive to detect and differentiate the rod-cone cells changes but requires prior dark adaptation. Patients with early AMD with good visual acuity are more tolerant of scotopic testing than intermediate AMD. Scotopic and mesopic testing is more sensitive in early AMD than intermediate AMD/ advanced AMD. Both MP1-S and S-MAIA are suitable for monitoring progression; however, S-MAIA has the advantage of fast test protocols with a dynamic stimuli range, which helps overcome the longer test duration in MP1-S for scotopic testing filter selection.

\section{Clinical implications}

Microperimeter use in clinical practice will aid in monitoring AMD progression. Studies suggest that structural and functional assessments such as a change in retinal thickness using optical coherence tomography, best-corrected visual acuity, and the foveal 
sensitivity (scotopic and mesopic microperimetry) should be combined to monitor AMD progression.

\section{Research}

Future research should focus on recruiting a cohort of dry and wet AMD patients at various stages and following them up regularly to understand mesopic and scotopic microperimetry in assessing disease progression. The significant limitation reported in the longitudinal studies was the total time to perform the test and the lack of dynamic stimuli. Software update and developing customized grids will help ease these limitations. Because most published studies were focused on the European population, similar or conflicting results might be expected if done on a diverse study population.

\section{Conclusion}

In conclusion, compared to structural changes, a reduced scotopic function over mesopic at baseline may be used as a functional biomarker to monitor early (drusen, reticular pseudodrusen) and intermediate AMD progression. Longitudinal follow-up studies, on the other hand, are required for more substantial evidence.

\begin{abstract}
Author contributions GM, PN, SBG, RR, RVE were involved in the study design. GM, PN contributed to the acquisition of data, and SBG verified the data. GM and SBG were involved in the interpretation of data. GM was involved in drafting the manuscript. PN, SBG, RVE, RR contributed to the critical revision of the manuscript. GM, PN, SBG, RVE, RR were involved in the approval of the final manuscript.
\end{abstract}

Funding Open access funding provided by Manipal Academy of Higher Education, Manipal. No funding was received to conduct the study.

Data availability Only published articles were acquired for this scoping review. Data supporting this review is publicly available.

\section{Declarations}

Conflict of interest None declared.

Ethical approval Ethical clearance was not obtained since there was no patient involvement.
Consent for publication All authors gave their consent for publication.

Open Access This article is licensed under a Creative Commons Attribution 4.0 International License, which permits use, sharing, adaptation, distribution and reproduction in any medium or format, as long as you give appropriate credit to the original author(s) and the source, provide a link to the Creative Commons licence, and indicate if changes were made. The images or other third party material in this article are included in the article's Creative Commons licence, unless indicated otherwise in a credit line to the material. If material is not included in the article's Creative Commons licence and your intended use is not permitted by statutory regulation or exceeds the permitted use, you will need to obtain permission directly from the copyright holder. To view a copy of this licence, visit http://creativecommons.org/licenses/by/4.0/.

\section{References}

1. Adelson JD, Bourne RRAA, Briant PS et al (2021) Causes of blindness and vision impairment in 2020 and trends over 30 years, and prevalence of avoidable blindness in relation to VISION 2020: the Right to sight: an analysis for the global burden of disease study. Lancet Glob Health 9:e144 e160. https://doi.org/10.1016/S2214-109X(20)30489-7

2. Wong WL, Su X, Li X et al (2014) Global prevalence of age-related macular degeneration and disease burden projection for 2020 and 2040: a systematic review and metaanalysis. Lancet Glob Health 2:e106-e116. https://doi.org/ 10.1016/S2214-109X(13)70145-1

3. Flaxman SR, Bourne RRA, Resnikoff S et al (2017) Global causes of blindness and distance vision impairment 1990-2020: a systematic review and meta-analysis. Lancet Glob Health 5:e1221-e1234. https://doi.org/10.1016/ S2214-109X(17)30393-5

4. Lindblad AS, Kassoff A, Kieval S et al (1999) The agerelated eye disease study (AREDS): design implications AREDS report no. 1. Control Clin Trials 20:573-600. https://doi.org/10.1016/S0197-2456(99)00031-8

5. Ferris FL, Wilkinson CP, Bird A et al (2013) Clinical classification of age-related macular degeneration. Ophthalmology 120:844-851. https://doi.org/10.1016/j.ophtha. 2012.10.036

6. Chakravarthy U, Peto T (2020) Current perspective on agerelated macular degeneration. JAMA 324:794-795. https:// doi.org/10.1001/jama.2020.5576

7. Sunness JS, Gonzalez-Baron J, Applegate CA et al (1999) Enlargement of atrophy and visual acuity loss in the geographic atrophy form of age-related macular degeneration. Ophthalmology 106:1768-1779. https://doi.org/10.1016/ S0161-6420(99)90340-8

8. García-Layana A, Cabrera-López F, García-Arumí J et al (2017) Early and intermediate age-related macular degeneration: update and clinical review. Clin Interv Aging 12:1579-1587. https://doi.org/10.2147/CIA.S142685

9. Cabral De Guimaraes TA, Daich Varela M, Georgiou M, Michaelides M (2021) Treatments for dry age-related macular degeneration: therapeutic avenues, clinical trials 
and future directions. Br J Ophthalmol. https://doi.org/10. 1136/bjophthalmol-2020-318452

10. Midena E, Pilotto E (2017) Microperimetry in age: related macular degeneration. Eye 31:985-994. https://doi.org/10. 1038/eye.2017.34

11. Molina-Martín A, Pérez-Cambrodí RJ, Piñero DP (2018) Current clinical application of microperimetry: a review. Seminars Ophthalmol 33:620-628. https://doi.org/10.1080/ 08820538.2017.1375125

12. Pfau M, Jolly JK, Wu Z et al (2020) Fundus-controlled perimetry (microperimetry): application as outcome measure in clinical trials. Prog Retin Eye Res. https://doi.org/10. 1016/j.preteyeres.2020.100907

13. Nebbioso M, Barbato A, Pescosolido N (2014) Scotopic microperimetry in the early diagnosis of age-related macular degeneration: preliminary study. Biomed Res Int. https://doi.org/10.1155/2014/671529

14. Corvi F, Pellegrini M, Belotti M et al (2019) Scotopic and fast mesopic microperimetry in eyes with drusen and reticular pseudodrusen. Retina 39:2378-2383. https://doi. org/10.1097/iae.0000000000002335

15. Crossland MD, Luong VA, Rubin GS, Fitzke FW (2011) Retinal specific measurement of dark-adapted visual function: validation of a modified microperimeter. BMC Ophthalmol 11:5. https://doi.org/10.1186/1471-2415-11-5

16. Steinberg JS, Fitzke FW, Fimmers R et al (2015) Scotopic and photopic microperimetry in patients with reticular drusen and age-related macular degeneration. JAMA Ophthalmol 133:690-697. https://doi.org/10.1001/ jamaophthalmol.2015.0477

17. Steinberg JS, Sassmannshausen M, Pfau M et al (2017) Evaluation of two systems for fundus-controlled scotopic and mesopic perimetry in eye with age-related macular degeneration. Trans Vis Sci Tech 6:7. https://doi.org/10. 1167/tvst.6.4.7

18. Bowl W, Lorenz B, Jäger M, Friedburg C (2013) Improving detection of mild loss of retinal light increment sensitivity at the posterior pole with the Microperimeter MP1. Invest Ophthalmol Vis Sci 54:4666-4674. https://doi.org/10.1167/ iovs.12-11241

19. Microperimeter MP-3IRetina \& Glaucoma I NIDEK CO.,LTD. https://www.nidek-intl.com/product/ ophthaloptom/diagnostic/dia_retina/mp-3.html. Accessed 27 Apr 2021

20. Pfau M, Lindner M, Fleckenstein M et al (2017) Test-retest reliability of scotopic and mesopic fundus-controlled perimetry using a modified MAIA (macular integrity assessment) in normal eyes. Ophthalmologica 237:42-54. https://doi.org/10.1159/000453079

21. Welker SG, Pfau M, Heinemann M et al (2018) Retest reliability of mesopic and dark-adapted microperimetry in patients with intermediate age-related macular degeneration and age-matched controls. Invest Ophthalmol Vis Sci. https://doi.org/10.1167/iovs.18-23878

22. Pfau M, Lindner M, Gliem M et al (2018) Mesopic and darkadapted two-color fundus-controlled perimetry in patients with cuticular, reticular, and soft drusen. Eye 32:1819-1830. https://doi.org/10.1038/s41433-018-0183-3

23. Pondorfer SG, Heinemann M, Wintergerst MWM et al (2020) Detecting vision loss in intermediate agerelated macular degeneration: a comparison of visual function tests.
PLoS ONE 15:1-12. https://doi.org/10.1371/journal.pone. 0231748

24. Pfau M, Müller PL, von der Emde L et al (2020) Mesopic and dark-adapted two-color fundus-controlled perimetry in geographic atrophy secondary to age-related macular degeneration. Retina 40:169-180. https://doi.org/10.1097/ IAE.0000000000002337

25. Montesano G, Ometto G, Higgins BE et al (2020) Structurefunction analysis in macular drusen with mesopic and scotopic microperimetry. Trans Vis Sci Tech 9:1-14. https:// doi.org/10.1167/TVST.9.13.43

26. Sassmannshausen M, Steinberg JS, Fimmers R et al (2018) Structure-function analysis in patients with intermediate age-related macular degeneration. Invest Ophthalmol Vis Sci 59:1599-1608. https://doi.org/10.1167/iovs.17-22712

27. von der Emde L, Pfau M, Thiele S et al (2019) Mesopic and dark-adapted two-color fundus-controlled perimetry in choroidal neovascularization secondary to age-related macular degeneration. Trans Vis Sci Tech 8:7. https://doi. org/10.1167/tvst.8.1.7

28. Munn Z, Peters MDJ, Stern C et al (2018) Systematic review or scoping review? Guidance for authors when choosing between a systematic or scoping review approach. BMC Med Res Methodol 18:143. https://doi.org/10.1186/s12874018-0611-X

29. Madheswaran G, Nasim P, SVe R, et al (2021) OSF Registries I Scotopic perimetry in age related macular degeneration: scoping review protocol. https://osf.io/zpqk6. Accessed 5 Mar 2021

30. Arksey H, O’Malley L (2005) Scoping studies: towards a methodological framework. Int J Social Res Method Theory Pract 8:19-32. https://doi.org/10.1080/ 1364557032000119616

31. Levac D, Colquhoun H, O’Brien KK (2010) Scoping studies: advancing the methodology. Implement Sci 5:69. https://doi.org/10.1186/1748-5908-5-69

32. Peters MDJ, Marnie C, Tricco AC et al (2021) Updated methodological guidance for the conduct of scoping reviews. JBI Evidence Implementation 19:3-10. https://doi. org/10.1097/XEB.0000000000000277

33. Mendeley Reference Manager. https://www.mendeley. com/reference-manager/library/all-references. Accessed 5 May 2021

34. Tricco AC, Lillie E, Zarin W et al (2018) PRISMA extension for scoping reviews (PRISMA-ScR): checklist and explanation. Ann Intern Med 169:467-473. https://doi.org/ 10.7326/M18-0850

35. Cassels N (2017) Quality-of-life and clinical outcomes in age-related macular degeneration. Cardiff University

36. Grewal MK (2021) Visual function in aging and age-related macular degeneration including subretinal drusenoid deposits. UCL (University College London)

37. Steinberg JS, Sassmannshausen M, Fleckenstein M et al (2016) Correlation of partial outer retinal thickness with scotopic and mesopic fundus-controlled perimetry in patients with reticular drusen. Am J Ophthalmol 168:52-61. https://doi.org/10.1016/j.ajo.2016.04.025

38. Sassmannshausen M, Pfau M, Thiele S et al (2020) Longitudinal analysis of structural and functional changes in presence of reticular pseudodrusen associated with age- 
related macular degeneration. Invest Ophthalmol Vis Sci 61:19. https://doi.org/10.1167/IOVS.61.10.19

39. Sassmannshausen M, Zhou J, Pfau M et al (2021) Longitudinal analysis of retinal thickness and retinal function in eyes with large drusen secondary to intermediate age-related macular degeneration. Ophthalmol Retina 5:241-250. https://doi.org/10.1016/j.oret.2020.07.019

40. Chandramohan A, Stinnett SS, Petrowski JT et al (2016) Visual function measures in early and intermediate agerelated macular degeneration. Retina 36:1021-1031. https:// doi.org/10.1097/IAE.0000000000001002

41. Forte R, Cennamo GG, De Crecchio G, Cennamo GG (2013) Microperimetry of subretinal drusenoid deposits. Ophthalmic Res 51:32-36. https://doi.org/10.1159/ 000354117

42. Querques G, Massamba N, Srour M et al (2014) Impact of reticular pseudodrusen on macular function. Retina 34:321-329. https://doi.org/10.1097/IAE. 0b013e3182993df1

43. Pascolini D, Mariotti SP (2012) Global estimates of visual impairment: 2010. Br J Ophthalmol 96:614-618. https://doi. org/10.1136/bjophthalmol-2011-300539
44. Joachim NDL, Mitchell P, Kifley A, Jinwang J (2015) Incidence, progression, and associated risk factors of medium drusen in age-related macular degeneration findings from the 15-year follow-up of an Australian cohort. JAMA Ophthalmol 133:698-705. https://doi.org/10.1001/ jamaophthalmol.2015.0498

45. Chakravarthy U, Bailey CC, Scanlon PH et al (2020) Progression from early/intermediate to advanced forms of agerelated macular degeneration in a large UK Cohort: rates and risk factors. Ophthalmol Retina 4:662-672. https://doi. org/10.1016/j.oret.2020.01.012

46. Murdoch IE, Morris SS, Cousens SN (1998) People and eyes: statistical approaches in ophthalmology. Br J Ophthalmol 82:971-973. https://doi.org/10.1136/bjo.82.8.971

Publisher's Note Springer Nature remains neutral with regard to jurisdictional claims in published maps and institutional affiliations. 